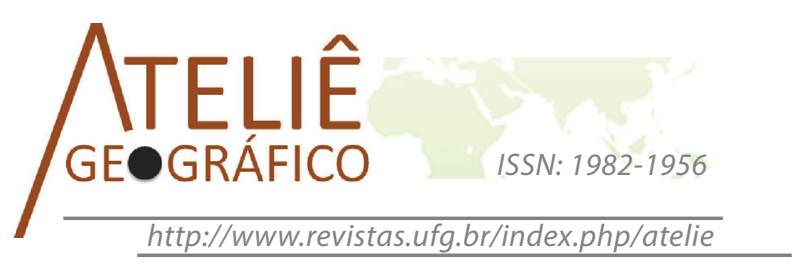

\title{
Análise geomorfológica em Unidades de Conservação da Natureza: Estação Ecológica Serra Geral do Tocantins - Estados do Tocantins e da Bahia
}

\author{
Geomorphological analysis of Nature Conservation Units: \\ Serra Geral do Tocantins Ecological Station - Tocantins \\ and Bahia
}

\section{Analyse géomorphologique en Unités de Conservation de la Nature: Serra Geral Station Écologique Tocantins - Tocantins et Bahia}

\author{
Sandro Sidnei Vargas de Cristo \\ Universidade federal do Tocantins \\ sidneicristo@uft.edu.br \\ Luis Eduardo de Souza Robaina \\ Universidade Federal de Santa Maria \\ lesrobaina@yahoo.com.br
}

\begin{abstract}
Resumo
Este artigo apresenta uma análise geomorfológica da Estação Ecológica Serra Geral do Tocantins. A base cartográfica foram cartas topográficas na escala 1:100.000 com apoio de imagens de satélites (LANDSAT 5) e de radar (SRTM/TOPODATA), trabalhadas no software Spring do INPE, versões 5.0.1 e 5.1.8. Os trabalhos de campo foram realizados por caminhos e estradas da região com uso de receptor GPS. Os estudos determinaram oito classes geomorfológicas, que são: a) planície de inundação, onde ocorrem significativas deposições sedimentares recentes; b) dunas eólicas, depósitos recentes pela ação do vento; c) vales abertos, associados a curso d'água em áreas planas com menos de $2 \%$ de declividade; d) vales fechados, quando a rede de drenagem encontra-se sob controle estrutural de lineamentos geológicos; e) colinas arenosas, representam relevo levemente ondulado com substrato de arenitos e solos arenosos; f) morros e morrotes, representadas por relevos residuais com topo arredondado; g) mesas e mesetas, caracterizadas como relevos residuais tabulares descontínuos e; h) chapada, que são relevos tabulares, topos planos e retilíneos, com grande continuidade de área.
\end{abstract}


Palavras-chave: Relevo; Geomorfologia; Unidade de Conservação da Natureza; Estação Ecológica Serra Geral do Tocantins

\begin{abstract}
This study develops in Ecological Station Serra Geral do Tocantins. The topographic base map at 1:100.000 scale with support for images from satellites LANDSAT 5 and SRTM radar images / TOPODATA. Were performed by the Spring software (INPE), versions 5.0.1 and 5.1.8. Field surveys were conducted through profiles made by paths and roads in the area with the use of GPS receiver equipment. The subdivision geomorphological defined eight classes, which are: a) floodplain, where there are significant recent sedimentary deposits; b) dunes, recent sediment by wind; c) open valleys, associated with stream in flatter areas with less than $2 \%$ slope; d) closed valleys, when the drainage system is structural control of geological lineaments; e) sandy hills, represent slightly wavy relief with substrate of sandstones and sandy soils; f) hills and buttes, represented by residual relief with rounded top; g) butte of flat top, characterized as a discontinuous and tabular forms; h) plateau, which are tabular reliefs, flat tops and with great continuity area.
\end{abstract}

Keywords: Relief; Geomorphology; Nature Conservation Unit; Ecological Station Serra Geral do Tocantins

\begin{abstract}
Résumé
Cette étude développe dans Station Serra Geral do Tocantins. Ont été utilisées cartes topographiques à l'échelle 1/100.000 avec support, images satellites Landsat 5 et radar (SRTM / TOPODATA), à partir de software Spring (INPE), versions 5.0.1 et 5.1.8. Le travail de terrain a été réalisée par des profils le long des chemins et des routes dans la région avec l'utilisation du récepteur GPS. Les études ont mesuré huit classes géomorphologiques, qui sont: a) plaine d'inondacion, où il ya des dépôts récents; b) dunes, des dépôts causée par le vent; c) vallées ouvertes, associés aux chenal de rivière dans les zones les plus plates avec moins de $2 \%$ de pente d) vallées fermées, lorsque le système de drainage est sous contrôle structurel des linéaments géologiques; e) collines sablonneuses, représenter relief légèrement ondulé avec un substrat de grès et de sols sableux; f) buttes et petites buttes, représentés par le relief résiduel; g) buttes témoin tabulaire, caractérisé que des formes et des reliefs tabulaires et isolée; h) plateau, qui sont reliefs tabulaires.

Mots-clés: Relief; Géomorphologie;Unité pour la Conservation de la Nature, Écologique Station Serra Geral do Tocantins.
\end{abstract}

\title{
Introdução
}

Desde o seu surgimento, o homem manteve uma relação de apropriação dos recursos fornecidos pela natureza, a qual foi crescendo à medida que as técnicas avançaram, ampliando a capacidade humana de intervenção. Segundo Ross (1992), todas as modificações inseridas pelo homem no ambiente natural alteram o equilíbrio da natureza.

Para Suertegaray (2003), a valorização do estudo da ação de cada processo tem desencadeado tendências e especialização, levando os pesquisadores a um nível de 
maior aproximação com outros de áreas afins. Esses contatos ao redor de uma temática específica geram amplo intercâmbio, havendo, na prática, assimilação de conteúdos e de técnicas que se mostram mais efetivas e precisas na resolução de problemas comuns.

Segundo Guerra e Marçal (2006) as Unidades de Conservação (UC) podem ser beneficiadas pelos conhecimentos geomorfológicos para os trabalhos de Zoneamento Ambiental e, em especial, a execução de Planos de Manejo (PM). Além disso, podem ser utilizadas para recuperação de áreas degradadas, desenvolvimento de técnicas adequadas ao desenvolvimento do turismo ecológico e a definição de trilhas e áreas a serem mais aproveitadas.

Conforme Casseti (2005), a Geomorfologia é um conhecimento específico, sistematizado que tem por objetivo analisar as formas do relevo, buscando compreender os processos pretéritos e atuais. Para Guerra (1993) Geomorfologia é a ciência que estuda as formas de relevo, tendo em vista a origem, estrutura, natureza das rochas, o clima da região e as diferentes forças endógenas e exógenas que, de modo geral, entram como fatores que influenciam o relevo terrestre.

Segundo Christofoletti (1974) a Geomorfologia representa a expressão espacial de uma superfície, compondo as diferentes configurações da paisagem morfológica, desta forma existe a oportunidade de planejar para preservar o ambiente e para usar racionalmente os recursos naturais. Ainda pode-se mencionar que a cartografia geomorfológica representa para geomorfologia um importante veículo de comunicação e de análise de resultados obtidos nos estudos das formas e compartimentação do relevo (LUPINACCI et al. 2003).

Segundo Barbosa, et al. (1984) até o ano de 1968, a experiência acumulada no Brasil sobre mapas geomorfológicos era pequena, desigual em escalas e geralmente apoiada em modelos estrangeiros. Estes mapas eram predominantemente baseados em aerofotos e elaborados por universidades.

Para Florenzano (2008) os sistemas de mapeamentos geomorfológicos nem sempre incluem todos os aspectos de relevo ou dão a eles a mesma ênfase e destaque. Deste modo, pode ser enfatizado que o mapeamento geomorfológico apresenta uma grande diversidade de procedimentos que podem ser aplicados na análise e compartimentação de modelagem do relevo.

Neste contexto, o presente estudo possui como principal objetivo a compartimentação e analise geomorfológica da Estação Ecológica Serra Geral do Tocantins (EESGT), como apoio em ações de planejamento e gestão ambiental.

AEESGT é uma UC integrante do Sistema Nacional de Unidades de Conservação (SNUC) - Lei n ${ }^{\circ} 9.985$ de 18/07/2000. Estação Ecológica que foi criada pelo Decreto Federal de 27 de setembro de 2001, com objetivo de proteger e preservar amostras dos ecossistemas de Cerrado, bem como propiciar o desenvolvimento de pesquisas científicas.

Geograficamente, a EESGT está localizada entre as coordenadas 10²5'31,08'

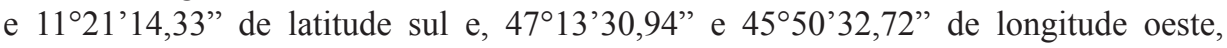


apresentando uma área aproximada de 707.144ha, sendo que cerca de 631.598ha ficam no Tocantins (TO), municípios de Mateiros, Ponte Alta do Tocantins, Almas e Rio da Conceição, e de 75.545ha ficam na Bahia (BA), município de Formosa do Rio Preto (Figura 1).

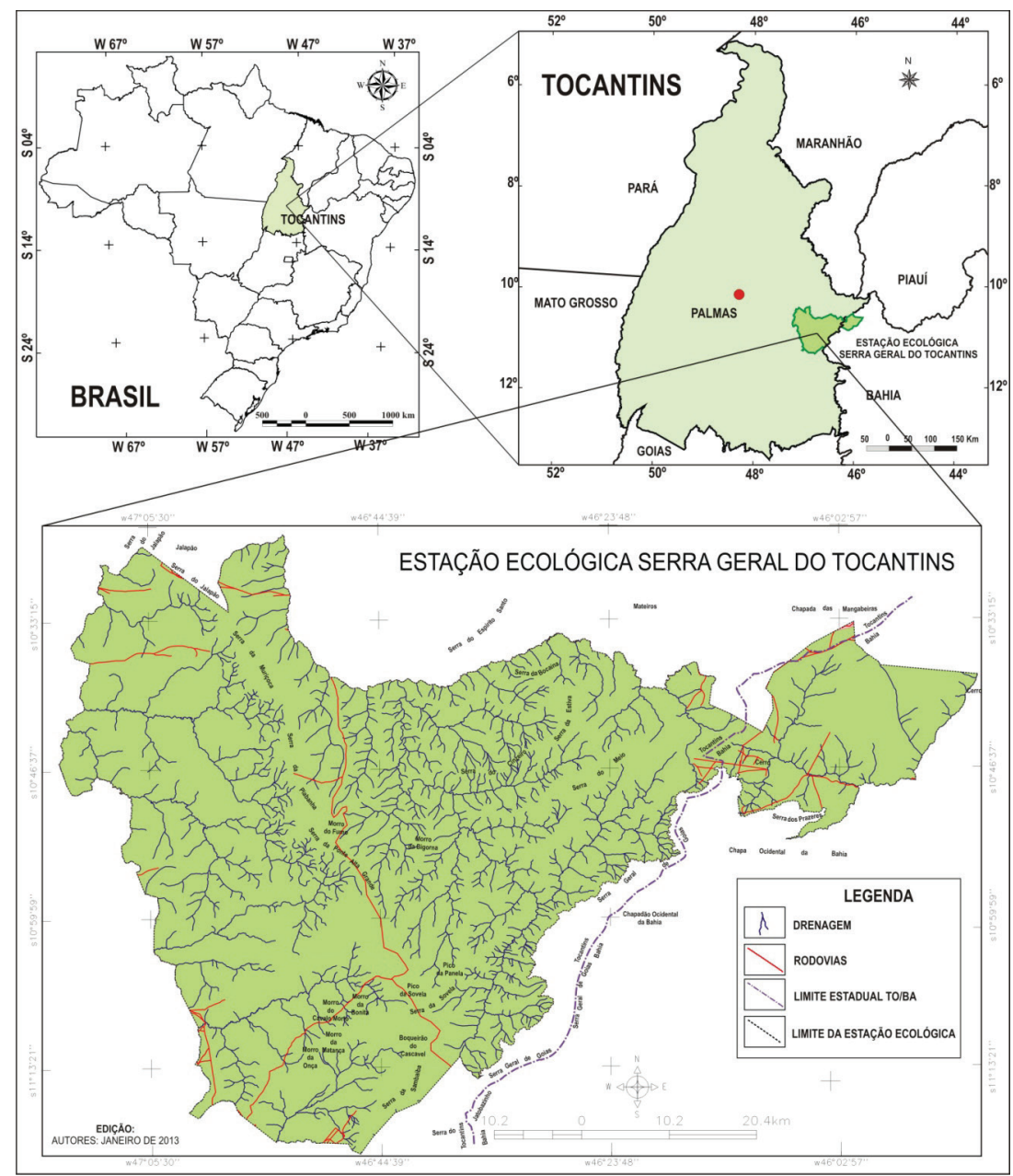

Figura 1. Localização da Estação Ecológica Serra Geral do Tocantins.

Fonte: Autores, janeiro de 2013.

A área de pesquisa faz parte do Corredor do Ecológico do Jalapão que abrange o Tocantins, Piauí, Maranhão e Bahia onde encontra-se um mosaico de Unidades de Conservação formado pela Estação Ecológica Serra Geral do Tocantins, o Parque Estadual do Jalapão, a ÁPA do Jalapão, o Parque Nacional das nascentes do Rio Parnaíba 
e a APA Serra da Tabatinga, sendo que atualmente, este mosaico de unidades representa o maior fragmento de Cerrado legalmente protegido no Brasil.

O Jalapão é a parte tocantinense das escarpas, rios e afluentes da bacia hidrográfica do Tocantins-Araguaia que tem sua denominação decorrente de uma das plantas mais comuns do Cerrado, a Jalapa encontrada na região (NATURATINS, 2003).

\section{Procedimentos Metodológicos}

O levantamento de material cartográfico foi realizado junto aos órgãos como Secretaria de Planejamento e Meio Ambiente do Tocantins (SEPLAN), Instituto Natureza do Tocantins (NATURATINS), Instituto Brasileiro de Geografia e Estatística (IBGE), Diretoria do Serviço Geográfico do Ministério do Exército (DSG), Companhia de Pesquisa de Recursos Minerais (CPRM), Instituto Nacional de Pesquisas Espaciais (INPE) e Instituto Chico Mendes de Conservação da Biodiversidade (ICMBio), entre outros com abrangência da área de pesquisa.

Como base cartográfica foram utilizadas as cartas topográficas elaboradas pela DSG e pelo IBGE, todas na escala 1:100.000. As imagens de satélites foram fornecidas pela (SEPLAN) - Diretoria de Zoneamento Ecológico Econômico (DZE). Sendo um mosaico de imagens do sensor Thematic Mapper (TM) do satélite LANDSAT 5, resolução espacial de 30 metros, de setembro de 2010, bandas espectrais 3, 4 e 5, órbitas ponto $221 / 67-221 / 68-220 / 67$ e 220/68.

As imagens de radar Shuttle Radar Topography Mission (SRTM) TOPODATA (Valeriano e Albuquerque, 2010), cenas equivalente a carta na escala 1:250.000, índice $10 / 45,10 / 48,10 / 465,11 / 45,11 / 48,11 / 464,12 / 48$, ambas com resolução espacial de 30 metros, foram obtidas junto ao Instituto Nacional de Pesquisas Espaciais (INPE).

Os trabalhos de campo, que contaram com apoio logístico do Instituto Chico Mendes de Conservação da Biodiversidade (ICMBio), foram feitos através de perfis realizados por caminhos e estradas da região com uso de equipamento receptor GPS (Figura 2). Nestes levantamentos foram realizadas descrição de solos e litologias, levantamento fotográfico dos aspectos físicos para caracterização temática e aferição das informações obtidas nas análises de cartas topográficas e imagens de satélite e radar.

Os trabalhos cartográficos foram realizados no Laboratório de Geoprocessamento (LABGEOP) do Curso de Geografia do Campus de Porto Nacional da Universidade Federal do Tocantins (UFT) em que se utilizou o software Sistema de Processamento de Informações Georreferenciadas (Spring) nas versões 5.0.1 e 5.1.8, do Instituto Nacional de Pesquisas Espaciais (INPE). Na edição final utilizou-se o software CorelDRAW X3 Graphic.

As classes geomorfológicas foram obtidas através de análise de imagens de satélite e radar (SRTM) apoiadas por diversos trabalhos de campo onde foram observadas as seguintes características: formas do relevo; rede de drenagem; substrato geológico; aspectos pedológicos e processos superficiais existentes. 


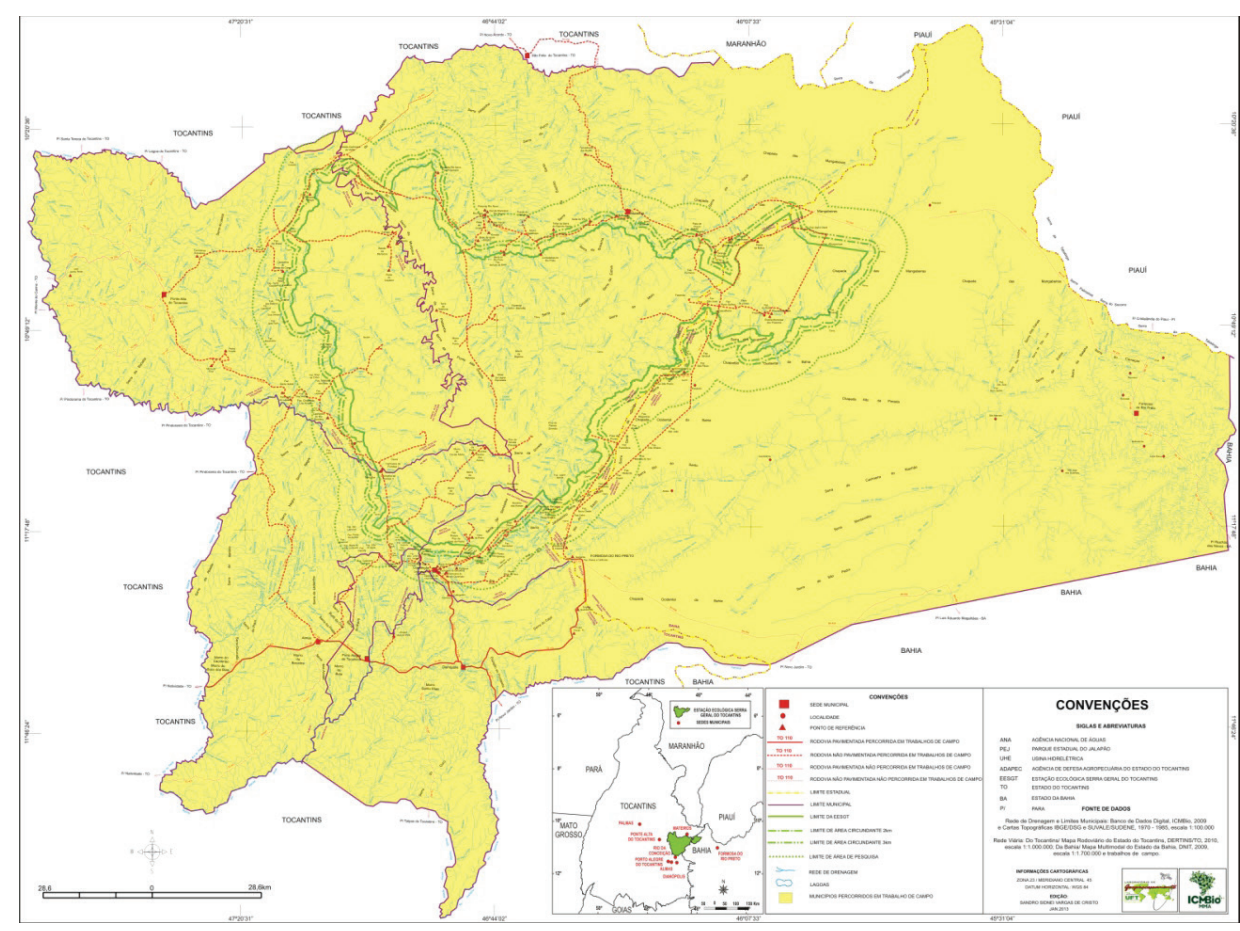

Figura 2. Mapa de Percursos de Campo realizados na Estação Ecológica Serra Geral do

Tocantins e entorno.

Fonte: Autores, janeiro de 2013.

\section{Caracterização Geomorfológica da EESGT}

As diferentes formas de relevo e das características da rede de drenagem foram descritas através das imagens de satélite e radar apoiadas por trabalhos de campo; o substrato geológico e aspectos pedológicos foram descritos conforme mapas préexistentes apoiados por trabalhos de campo; os processos superficiais, como sulcos, ravinas e voçorocas, foram identificados com trabalhos de campo apoiados por imagens de satélite e radar (SRTM).

A rede de drenagem da área de pesquisa (EESGT e 10km de entorno), abrange uma área de cerca 1.237,711ha e encontra-se inserida no divisor de águas de duas das principais bacias hidrográficas brasileiras dos Rios Tocantins-Araguaia e São Francisco.

Os rios que compõem as duas grandes bacias hidrográficas dos Rios TocantinsAraguaia e São Francisco, que drenam a área de pesquisa, conjuntamente, dão origem a quatro bacias hidrográficas menores (elementares), porém com grande influência no escoamento regional (Figura 3). 


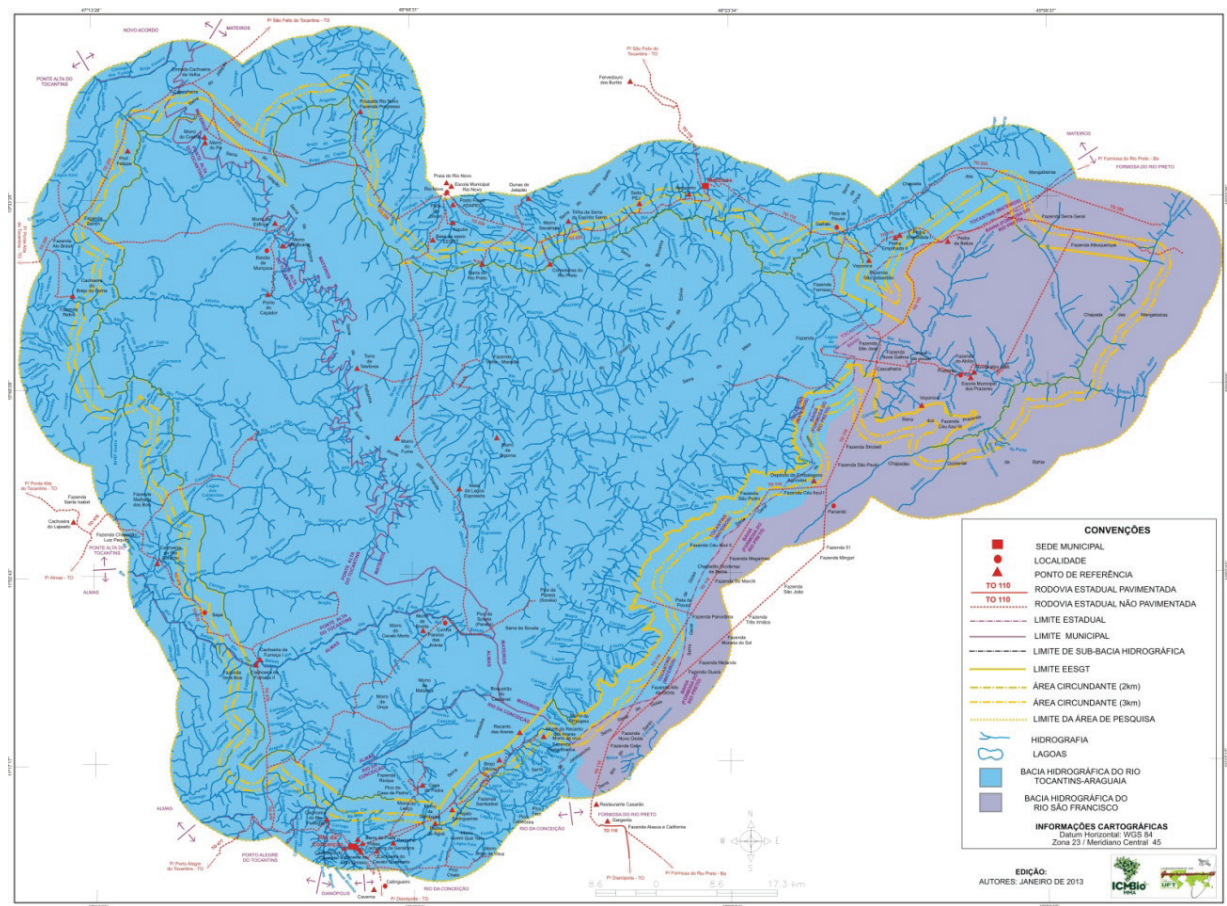

Figura 3. Mapa Hidrográfico com abrangência das bacias hidrográficas dos Rios Tocantins Araguaia e São Francisco.

Fonte: Autores, janeiro de 2013

Estas são as bacias hidrográficas do Rio Sono, do Rio das Balsas e do Rio Manoel Alves (integram a Bacia Hidrográfica do Rio Tocantins - Araguaia) e do Rio Preto (integra a Bacia Hidrográfica do Rio São Francisco).

Com relação ao relevo observa-se uma variação altimétrica entre 300 a 900m, apresentando uma amplitude altimétrica de $600 \mathrm{~m}$, onde a menor cota se encontra junto à planície de inundação do Rio Vermelho, localizada na sua porção noroeste e a maior cota se encontra junto as formas de relevo da Serra Geral, localizada na porção sudeste da área.

Geologicamente ocorrem, em mais de $90 \%$ da área de estudo, as rochas sedimentares da Bacia Sedimentar Sanfranciscana, representada por arenitos do Grupo Urucuia. Além dessas, ocorrem na porção oeste, rochas sedimentares da Bacia do Parnaíba e na porção sudoeste uma pequena exposição de xistos micáceos e calcosilicatadas do embasamento. 


\section{Identificação e Descrição das Feições geomorfológicas da EESGT}

Os estudos permitiram identificar oito classes presentes na área de estudo: Planície de Inundação, Dunas Eólicas, Vales Abertos, Vales Fechados, Colinas Arenosas, Morros e Morrotes, Mesas e Mesetas e a Chapada (Figura 4 e Quadro 1).

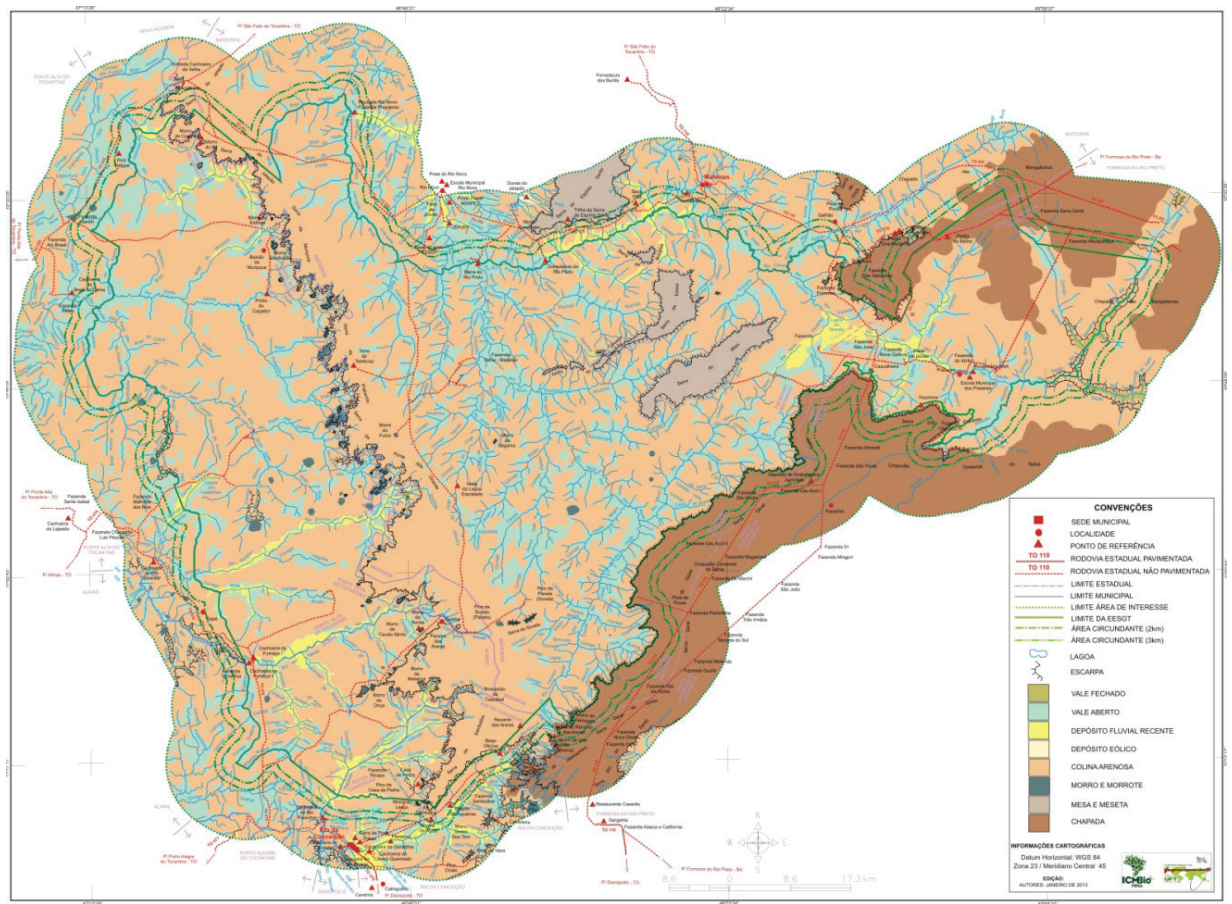

Figura 4. Mapa geomorfológico da Estação Ecológica Serra Geral do Tocantins (EESGT) e entorno.

Fonte: Autores, janeiro de 2013.

Quadro 1. Classes definidas no mapeamento geomorfológico.

\begin{tabular}{|l|r|r|}
\hline Classes & Área $\mathbf{( k m}^{\mathbf{}} \mathbf{)}$ & Porcentagem (\%) \\
\hline Planície de Inundação & 360,4 & 2,9 \\
\hline Dunas Eólicas & 1,8 & 0,01 \\
\hline Vales Abertos & $2.396,0$ & 19,4 \\
\hline Vales Fechados & 38,0 & 0,4 \\
\hline Colinas Arenosas & $7.434,3$ & 60 \\
\hline Morros e Morrotes & 53,3 & 0,4 \\
\hline Mesas e Mesetas & 266,0 & 2,2 \\
\hline Chapada & $1.827,3$ & 14,7 \\
\hline Total & $12.377,1$ & 100 \\
\hline
\end{tabular}

Fonte: Autores, 2013. 
A área definida como Planície de Inundação abrange desde as áreas de depósitos de barras de pontal até as planícies de inundações propriamente ditas, onde ocorrem significativas deposições sedimentares recentes. Estes depósitos são oriundos de processos erosivos fluviais que ocorrem nas cabeceiras de drenagens proporcionando deposição nas áreas baixas, mais a jusantes (Figura 5A). Esta classe corresponde a 2,9\% da área de pesquisa e se distribui em praticamente todos os setores da área, associadas aos vales abertos.

Na porção norte, na base da Serra do Espírito Santo, junto ao Riacho da Areia, os abundantes depósitos fluviais são retrabalhados pela ação do vento gerando uma feição muito característica que são as "Dunas do Jalapão". Essa feição ocorre em relevo suave ondulado com significativa deposição sedimentar recente ocasionado pela ação do vento. Sua origem está ligada ao retrabalhamento de depósitos arenosos, depositados por processos aquosos e pelo vento na base de encostas escarpadas (Figura 5B).
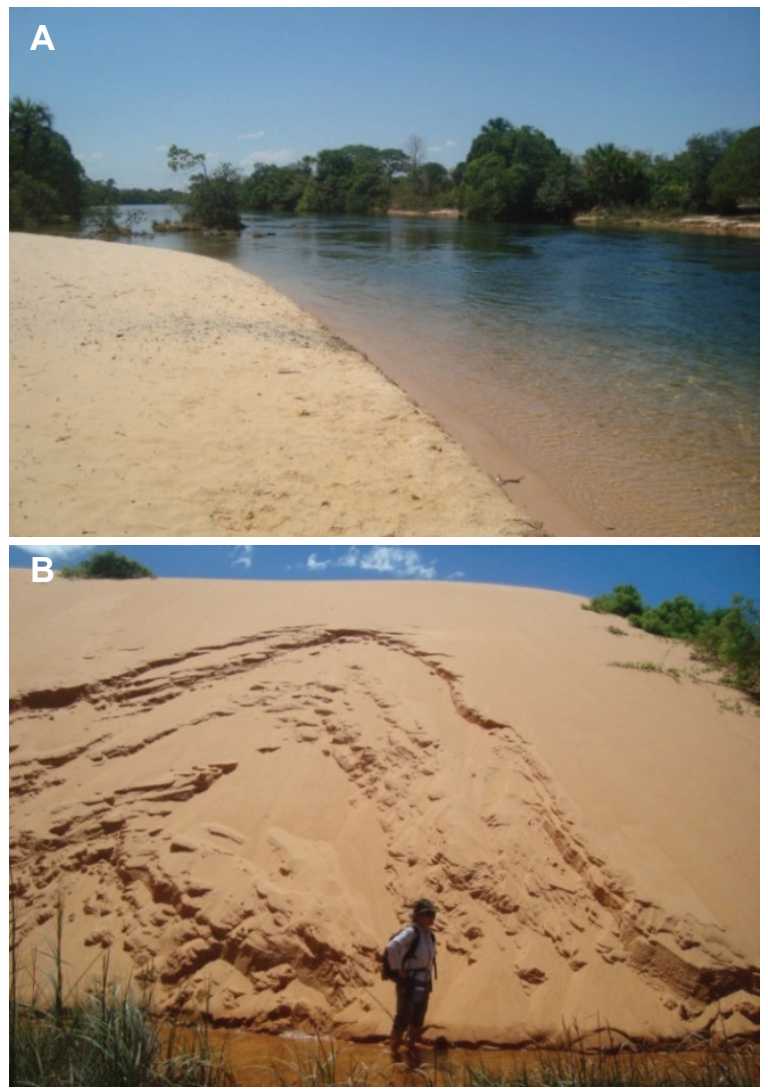

Figura 5. Barra de pontal na calha do Rio Novo, Mateiros (A) e Duna Eólica (Dunas do Jalapão), Mateiros (B).

Fotos: Autores, outubro de 2011. 
Os Vales Abertos se caracterizam como relevos planos com menos de $2 \%$ de declividade onde ocorrem processos de deposição de sedimentos localizados junto às planícies de inundações dos cursos fluviais que compõem a rede de drenagem local (Figura 6A). É uma classe geomorfológica que compreende cerca de 19,4\% da área de pesquisa.

Os Vales Fechados são feições caracterizadas como canais encaixados que formam os cursos de água que compõem a rede de drenagem local (Figura 6B).
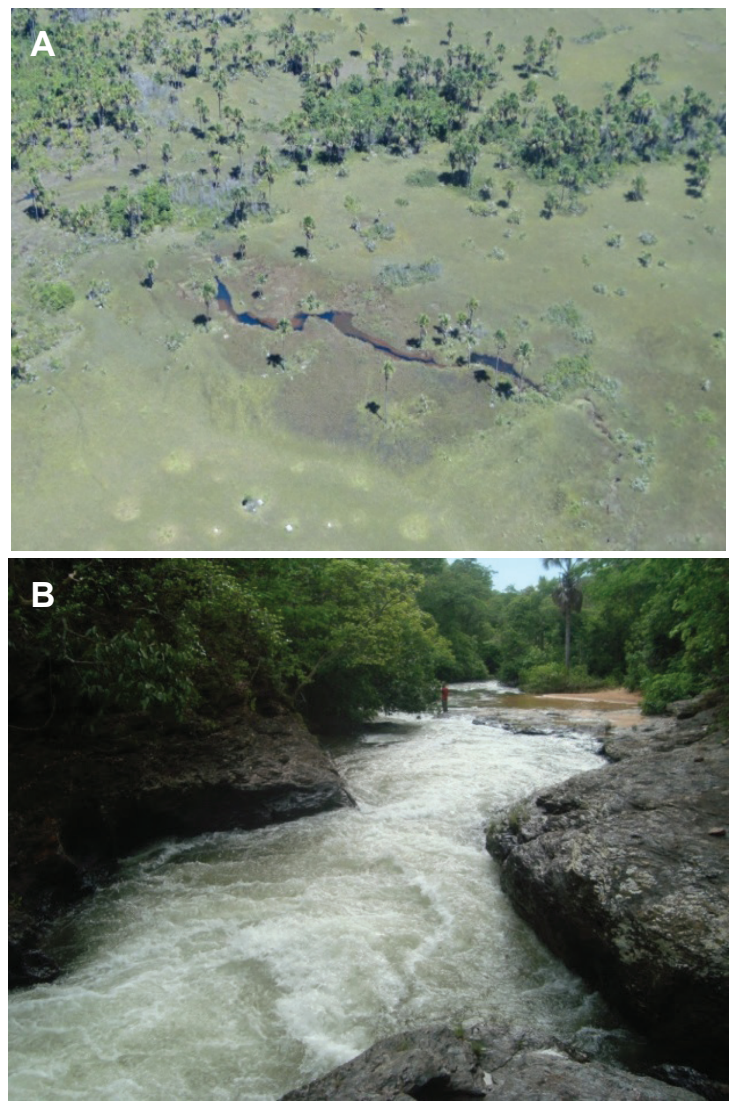

Figura 6. Vale Aberto com relevo plano em área de vereda (A) e Vale Fechado do Rio Manoel Alves encaixado no embasamento de rochas metamórficas, Rio da Conceição (B).

Foto (A): Côrtes, 2010 e Foto (B): Autores, outubro de 2010.

$\mathrm{Na}$ presente feição, a rede de drenagem encontra-se sob controle estrutural representado por lineamentos geológicos. Esta classe fica restrita em algumas calhas de drenagens que se distribuem na área de pesquisa, as quais estão associadas à litologias mais resistentes a erosão, como observadas nos rios Manoel Alves e Manoel Alvinho, localizados no setor sul. 
As Colinas Arenosas se caracterizam como um relevo levemente ondulado com declividade entre 5 e $15 \%$, em média $8 \%$, amplitudes entre $40 \mathrm{~m}$ e $60 \mathrm{~m}$, substrato de arenitos e solos do tipo Neossolos Quartzarênicos (Figura 7A). Esta classe é predominante na área de pesquisa, correspondendo a cerca de $60 \%$, distribuindo-se por praticamente todos os setores.

Os Morros e Morrotes são relevos residuais com topo arredondado, com vertentes de inclinação superiores a 15\% e, alguns com feições ruiniformes (Figura 7B). São feições que possuem um substrato arenítico resistente pela presença de cimentos ferruginosos com predominância de solos dos tipos Cambissolo e Neossolo litólico. Esta classe geomorfológica correspondendo a $0,4 \%$ da área de pesquisa distribuindo-se em diversos setores com concentração na sua porção central, em especifico nas proximidades da linha de escarpa da Serra da Muriçoca.

As Mesas e Mesetas formam uma feição típica da área e são caracterizadas como relevos residuais tabulares descontínuos, formando elevações de topos planos com vertentes íngremes.
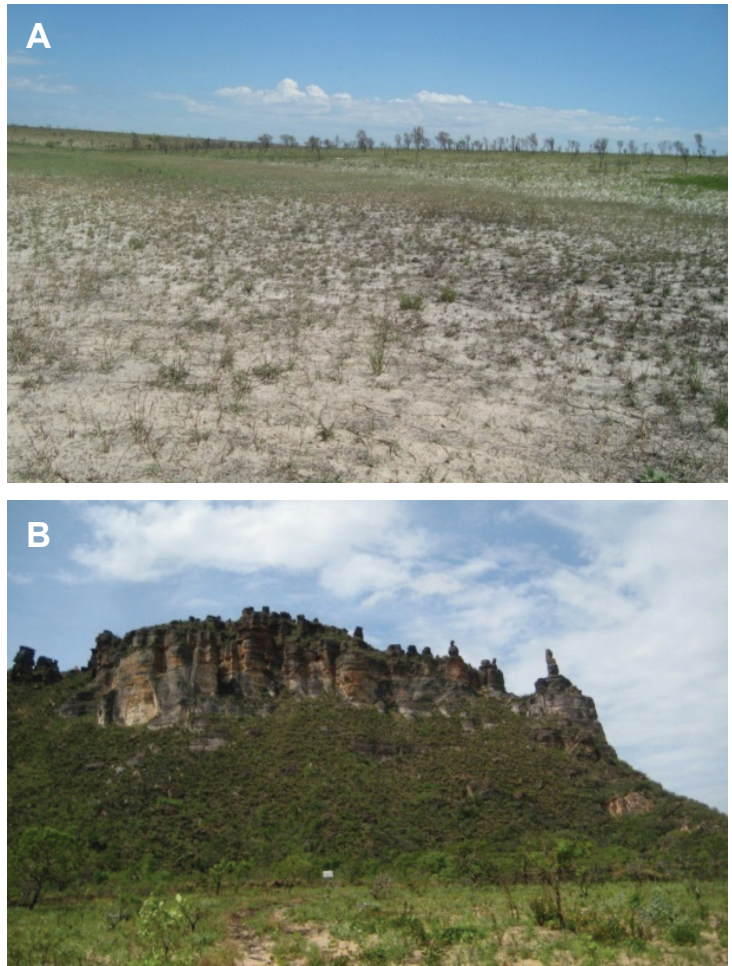

Figura 7. Colinas Arenosas da porção central da área de pesquisa (A) e Relevo Residual (Morro do Fumo) presente na porção central da área de pesquisa (B).

Foto (A): Autores, outubro de 2011 e Foto (B): Kabashima, outubro de 2011. 
As Mesetas são determinadas por apresentarem amplitudes altimétricas menores que $100 \mathrm{~m}$, enquanto que, as Mesas apresentam amplitudes maiores que 100m (Figura 8A). Estas feições são formadas por rochas sedimentares estratificadas, topos planos e encostas escarpadas, características de relevos tabulares que se apresentam no terreno como resquícios de rochas com maior coesão, dado por material cimentante preenchendo os poros, especialmente, sílica e óxido de ferro, o que permite a manutenção parcial de suas estruturas.

$\mathrm{Na}$ base das encostas escarpadas ocorre acumulação de material rochoso originado pela própria desagregação das porções superiores das mesmas.

Esta classe corresponde a 2,2\% da área de pesquisa se distribuindo nos setores centro e norte como a Serra da Bocaína, a Serra do Cinzeiro e a Serra do Espírito Santo.

As Chapadas se caracterizam por relevos tabulares, topos planos e retilíneos, com grande continuidade de área, originadas por recuo de escarpas. Possuem um substrato arenítico, relativamente, resistente pela presença de cimentos ferruginosos. Os solos são bem desenvolvidos, predominando, os solos do tipo Latossolo.

Nessa classe ocorrem as maiores altitudes, da área de pesquisa, as quais apresentam na base das encostas escarpadas uma acumulação de material rochoso originado pela própria desagregação das Chapadas. Abrange cerca de 14,7\% da área de pesquisa, distribuindo-se nos setores sudeste, leste e nordeste nas regiões conhecidas como a Serra das Mangabeiras e a Serra Ocidental da Bahia (Figura 8B).
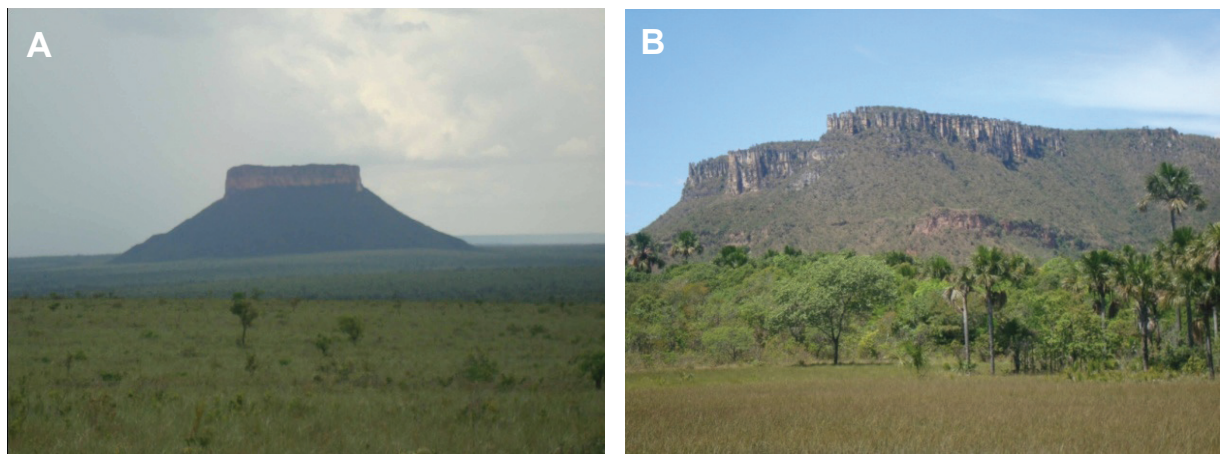

Figura 8. Feições de relevo com topo plano, Mesa como o Morro da Bigorna (A)

e Chapada Ocidental da Bahia com relevo tabular de topo plano (B).

Foto (A): C. Barreto, agosto de 2010 e Foto (B): Autores, agosto de 2011.

As escarpas são locais onde se encontram grande parte das cabeceiras de drenagens e os intensos processos erosivos que servem de fonte de materiais sedimentares que se depositam nas áreas baixas e planas. Podem ser observadas nas encostas das mesas e mesetas dos setores centro e norte (Serras da Bocaína, do Cinzeiro e do Espírito Santo), nas Chapadas dos setores sudeste, leste e nordeste (Serras das Mangabeiras e 
Ocidental da Bahia) e no principal patamar de dissecação que atravessa a área, no sentido sudeste - noroeste (Serra da Muriçoca) (Figura 9A).

Tambémé perceptível, na base dos relevos tabulares, a existência de significativos depósitos de Talús e Colúvios formados por depósitos de blocos de rochas e fragmentos sedimentares originados por intensos processos erosivos (Figura 9B).
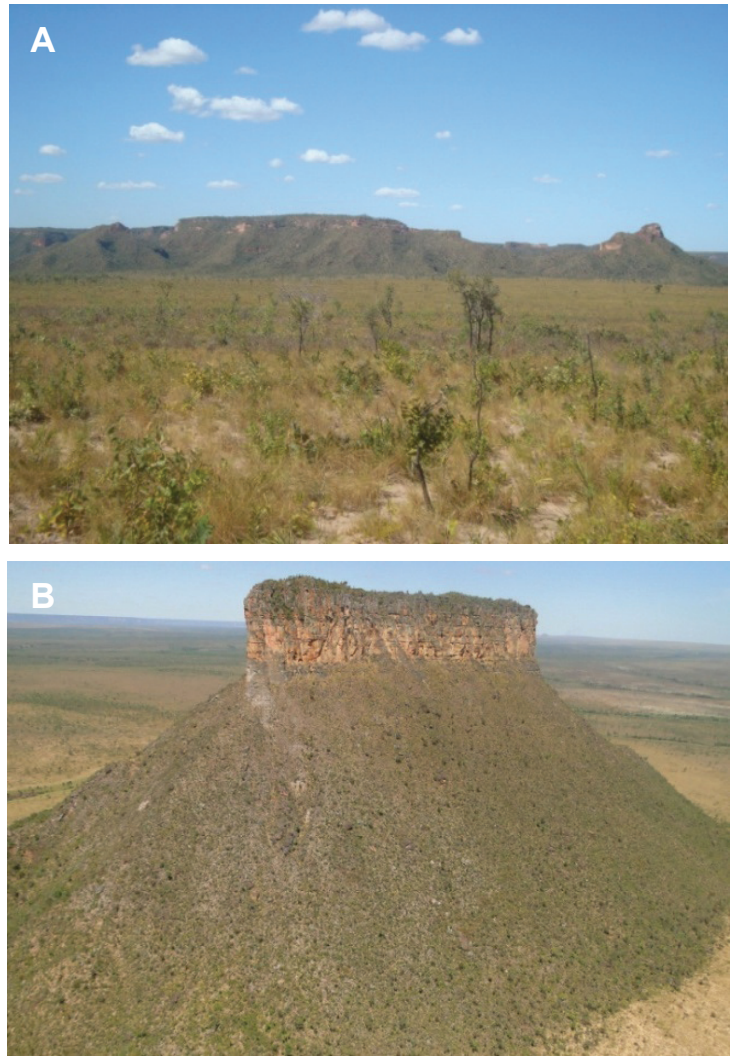

Figura 9. Visualização da escarpa na Serra da Muriçoca, porção noroeste da área de pesquisa (A) e Deposito de Talús e Colúvios, na base do morro da Bigorna, porção central da área de pesquisa (B).

Foto (A): Autores, agosto de 2011 e Foto (B): Côrtes, 2010.

\section{Evolução do Relevo e o desenvolvimento das formas}

De modo geral, a evolução do relevo, na área de pesquisa, ocorre pela erosão regressiva com recuo das escarpas da Serra da Muriçoca, da Serra Geral e da Chapada das Mangabeiras. 
A ação de processos erosivos que incidem sobre as rochas locais fragmentam as porções mais friáveis (erosão diferencial), ocasionando o transporte dos sedimentos, restando às porções mais resistentes que dão as formas específicas.

A figura 10 apresenta um croqui esquemático da progressão do relevo e a visualização das formas através de fotografias, que procuram representar o processo de regressão erosiva que gera as diferentes formas características da área.

O processo de recuo da escarpa segue lineamentos estruturais onde a rede de drenagem se encaixa.

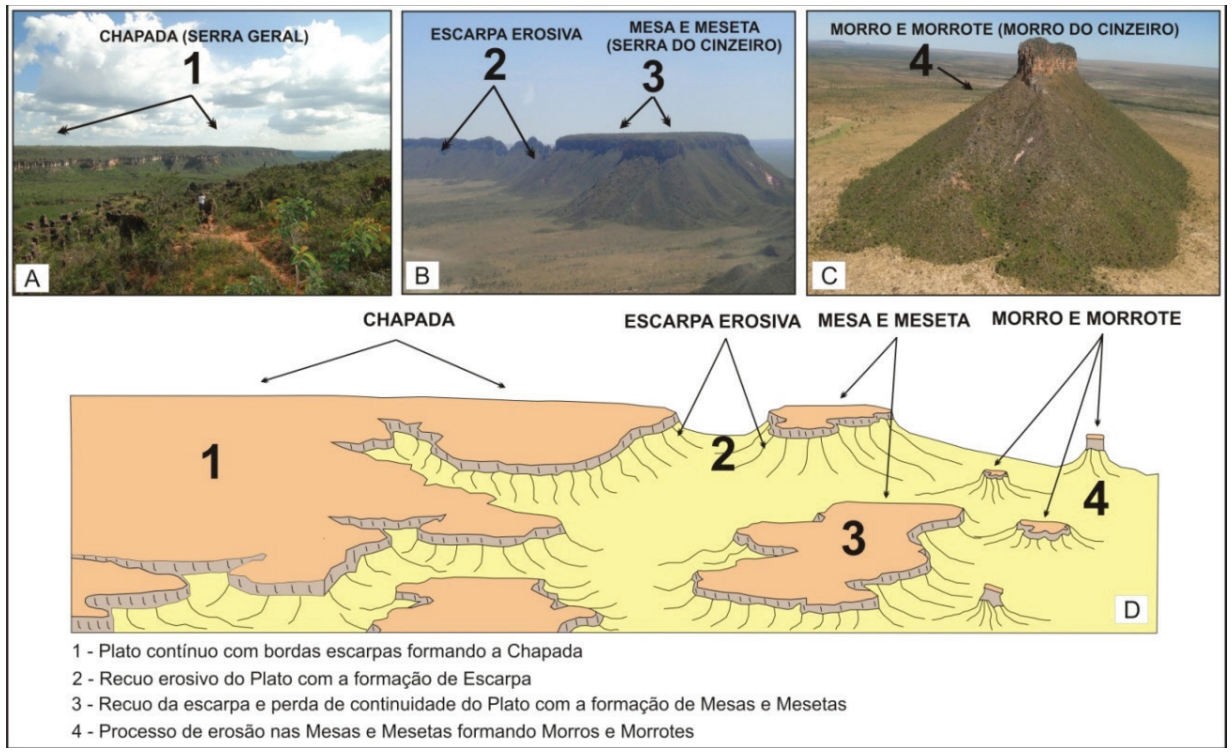

Figura 10. Croqui Esquemático da Evolução do Relevo na região.

Fonte: (A) M. Costa, 2013; (B) Côrtes, 2010; (C) Côrtes, 2010; (D) Adaptado de HAMBLIN (1985).

De maneira predominante, as feições apresentam, na porção superior, camadas de rochas areníticas estratificadas com coloração esbranquiçada, pela cimentação silicosa, associadas com camadas de rochas areníticas estratificadas de coloração avermelhadas, pela pigmentação de óxido de ferro, que gera as formas de topo tabular das elevações isoladas pelo recuo da escarpa.

Do processo de erosão regressiva restam porções que são definidas por um topo plano e encostas íngremes denominadas de mesas e mesetas. Como os processos erosivos seguem zonas de fraqueza estrutural da rocha podem avançar para formas de relevo com topo arredondados ou aciculares que são denominados de morros e morrotes. 
Outras vezes os processos erosivos diferenciais desenvolvem formas de topos constituídos por um conjunto de pináculos, que associados ao tombamento de blocos e matacões na base da encosta geram formas ruiniformes típicas.

\section{Considerações Finais}

A geomorfologia representa os diferentes modelados de relevo e, consequentemente, é o fator elementar na caracterização ambiental. Ainda é um instrumento de análise e de síntese da pesquisa geomorfológica e serve como importante base para o planejamento e gestão ambiental, pois aborda a integração e as relações que se estabelecem entre o relevo, solos, litologias e os processos atuantes que compõe os elementos geomorfológicos, frente aos processos envolvidos na organização da paisagem local.

O presente trabalho fez uma analise dos elementos do meio físico e os processos superficiais que condicionam e formam a geomorfologia da Unidade de Conservação da Natureza (UC), permitindo maior compreensão do valor ecológico-ambiental dos aspectos abióticos da Estação Ecológica Serra Geral do Tocantins (EESGT) e área de entorno.

\section{Referências}

BARBOSA, G. V.; SILVA, T. C.; NATALI FILHO, T; DEL'ARCO, D. M.; COSTA, R. C. R.. Evolução da metodologia para mapeamento geomorfológico do Projeto RadamBrasil. Boletim Técnico, Série Geomorfologia. Salvador n. 1, p. 187, out. 1984.

BRASIL. Lei $n^{\circ}$ 9.985. Brasília: 18 de julho de 2000. Disponível em: <http://www. planalto.gov.br/ccivil_03/Leis/L9985.htm>. Acesso em: 24 fev. 2011

CASSETI, V. Geomorfologia. [S.1.]: [2005]. Disponível em: http://www.funape.org.br/ geomorfologia/. Acessado em 29/11/2011.

CHRISTOFOLETTI, A. Geomorfologia. São Paulo: Edgard Blücher, Ed. Da Universidade de São Paulo, 1974. 150p

FLORENZANO, T. G.. Cartografia. In: FLORENZANO, T. G. (Org.) Geomorfologia conceitos e tecnologias atuais. São Paulo: Oficina de Textos, 2008. p. 105-128.

GUERRA, A. J. T. Dicionário Geológico Geomorfológico. Rio de Janeiro: IBGE, $1^{\circ}$ edição, 1993. 446p.

GUERRA, A. J. T. e MARÇAL, M. S. 2006. Geomorfologia Aplicada ao Turismo. In: Geomorfologia Ambiental. Rio de Janeiro: Bertrand Brasil, p. 42-46.

HAMBLIN, W. K. The Earth's Dynamics Systems. Minnesota: Burgess Publishing, 4 edição, 1885. 528p. 
LUPINACCI, C. M., MENDES, I. A., SANCHEZ, M. S. A Cartografia do Relevo: Uma Análise Comparativa de Técnicas de Gestão Ambiental. In: Revista Brasileira de Geomorfologia, Ano 4, n 1, UGB, 2003, p 1-9.

NATURATINS. Plano de Manejo da APA do Jalapão. Palmas: Instituto da natureza do Tocantins, 2003.

VALERIANO, M. de M. e ALBUQUERQUE, P. C. G. de. TOPODATA: Processamento dos dados SRTM. São José dos Campos - SP: INPE, 2010. Disponível em http://www. dsr.inpe.br/topodata/documentos.php. Acessado em janeiro de 2010.

SANDro Sidnei Vargas de Cristo

Possui Graduação em Geografia pela Universidade Federal de Santa Maria, Mestrado em Geografia pela Universidade Federal de Santa Catarina e Doutorado em Geografia pela Universidade Federal do Rio Grande do Sul. Atualmente é professor Adjunto II do Curso de graduação e Pós-Graduação em Geografia do Campus de Porto Nacional da Universidade Federal do Tocantins/UFT.

Campus de Porto Nacional. Rua 03, Quadra 17, Lote 11, S/N $\mathbf{N}^{\circ}$, Setor Jardim dos Ipês, Porto Nacional, Tocantins CEP: 77500-000.

Email: sidneicristo@uft.edu.br

\section{Luís Eduardo de Souza Robaina}

Possui graduação em Geologia pela Universidade do Vale do Rio dos Sinos, mestrado e doutorado em Geociências pela Universidade Federal do Rio Grande do Sul e Pós-Doutorado na Universidade do Porto, Portugal e na Universidade du Maine, Le Mans/França. Atualmente é professor/pesquisador colaborador do programa de Pós-graduação em Geografia da Universidade Federal do Rio Grande do Sul e professor titular da Universidade Federal de Santa Maria, do curso de Geografia e do programa de Pós-graduação em Geografia e Geociências. LAGEOLAM. Prédio 17, CEP 97105-900 - Santa Maria, RS - Brasil. Email: lesrobaina@yahoo.com.br

Recebido para publicação em julho de 2014 Aprovado para publicação em novembro de 2015 